\title{
RABIA EN Potos flavus IDENTIFICADOS EN EL DEPARTAMENTO DE MADRE DE DIOS, PERÚ
}

\author{
Elena Vargas-Linares ${ }^{1, a}$, Franco Romaní-Romaní1,b, Ricardo López-Ingunza ${ }^{2, c}$, \\ Juan Arrasco-Alegre ${ }^{1, d}$, Martín Yagui-Moscoso $0^{1, b}$
}

RESUMEN

El Potos flavus es un mamífero nocturno que habita en bosques neotropicales desde Centroamérica hasta Sudamérica. Se realizó un estudio de cuatro casos de rabia en Potos flavus ocurridos desde abril de 2012 en el departamento de Madre de Dios en Perú, captados como parte de la vigilancia epidemiológica. Los análisis realizados en el laboratorio de referencia regional de Madre de Dios determinaron presencia de antígeno del virus de la rabia en tres de las muestras de tejido encefálico, dichos resultados fueron corroborados en el Laboratorio de Zoonosis Virales del Instituto Nacional de Salud del Perú mediante inmunofluorescencia directa, la tipificación no identificó ninguna de las variantes conocidas en murciélagos o en perros. La ocurrencia de cuatro casos de rabia en Potos flavus suma evidencias de la emergencia de un nuevo reservorio del virus de la rabia y que ha sido reportada previamente en el mismo departamento el año 2007.

Palabras claves: Rabia; Vigilancia epidemiológica; Técnica de inmunofluorescencia directa (fuente: DeCSS BIREME).

\section{RABIES IN Potos flavus IDENTIFIED IN MADRE DE DIOS, PERU}

\section{ABSTRACT}

The Potos flavus is a nocturnal mammal that lives in neotropical forests from Central America to South America. A study of four cases of rabies in Potos flavus was conducted; these occurred in April 2012 in the Madre de Dios region in Peru and were collected as part of epidemiological surveillance. The analysis performed in the regional reference laboratory of Madre de Dios determined the presence of the rabies virus antigen in three of the brain tissue samples. Results were verified in the Laboratory of Viral Zoonoses of the Peruvian National Institute of Health by direct immunofluorescence. The typification did not identify any of the known variants in bats or dogs. The occurrence of four cases of rabies in Potos flavus adds evidence of the emergence of a new reservoir of the rabies virus previously reported in the same region in 2007.

Key words: Rabies; Epidemiological surveillance; Fluorescent antibody technique, direct (source: MeSH NLM).

\section{INTRODUCCIÓN}

El virus de la rabia es un clásico patógeno zoonótico que produce un cuadro de encefalitis viral aguda (1). Tiene un amplio rango de hospederos y puede, potencialmente, infectar a cualquier mamífero. En el periodo 2010-2012, el $41,4 \%$ de casos de rabia humana en Latinoamérica y el Caribe procedieron del Perú. En el 2012, en la región de las Américas, se registraron 24 casos de rabia humana, once de los cuales correspondieron a rabia transmitida por murciélagos (diez procedentes de Perú y uno de Brasil) ${ }^{(2-4)}$.
En el Perú, los brotes de rabia silvestre han sido documentados en poblaciones humanas residentes de la selva, la mayoría de casos estuvieron asociados con el murciélago hematófago común (Desmodus rotundus) ${ }^{(3,5-7)}$, también existe evidencia de circulación del virus en murciélagos no hematófagos como Tadarida brasiliensis y Lasiurus cinereus lo cual sugiere trasmisión interespecie ${ }^{(8)}$.

El Potos flavus, conocido comúnmente como "chosna" (Figura 1), es un mamífero arbóreo y frugívoro que ocupa los bosques tropicales desde México hasta

\footnotetext{
Dirección General de Epidemiología, Ministerio de Salud. Lima, Perú.

Instituto Nacional de Salud. Lima, Perú

Médico veterinario epidemiólogo, ${ }^{\mathrm{b}}$ médico cirujano, ${ }^{\mathrm{c}}$ médico veterinario, ${ }^{\mathrm{d}}$ médico epidemiólogo

Recibido: 24-09-13 Aprobado: 11-12-13
}

Citar como: Vargas-Linares E, Romaní-Romaní F, López-Ingunza R, Arrasco-Alegre J, Yagui-Moscoso M. Rabia en Potos flavus identificados en el departamento de Madre de Dios, Perú. Rev Peru Med Exp Salud Publica. 2014;31(1):88-93. 

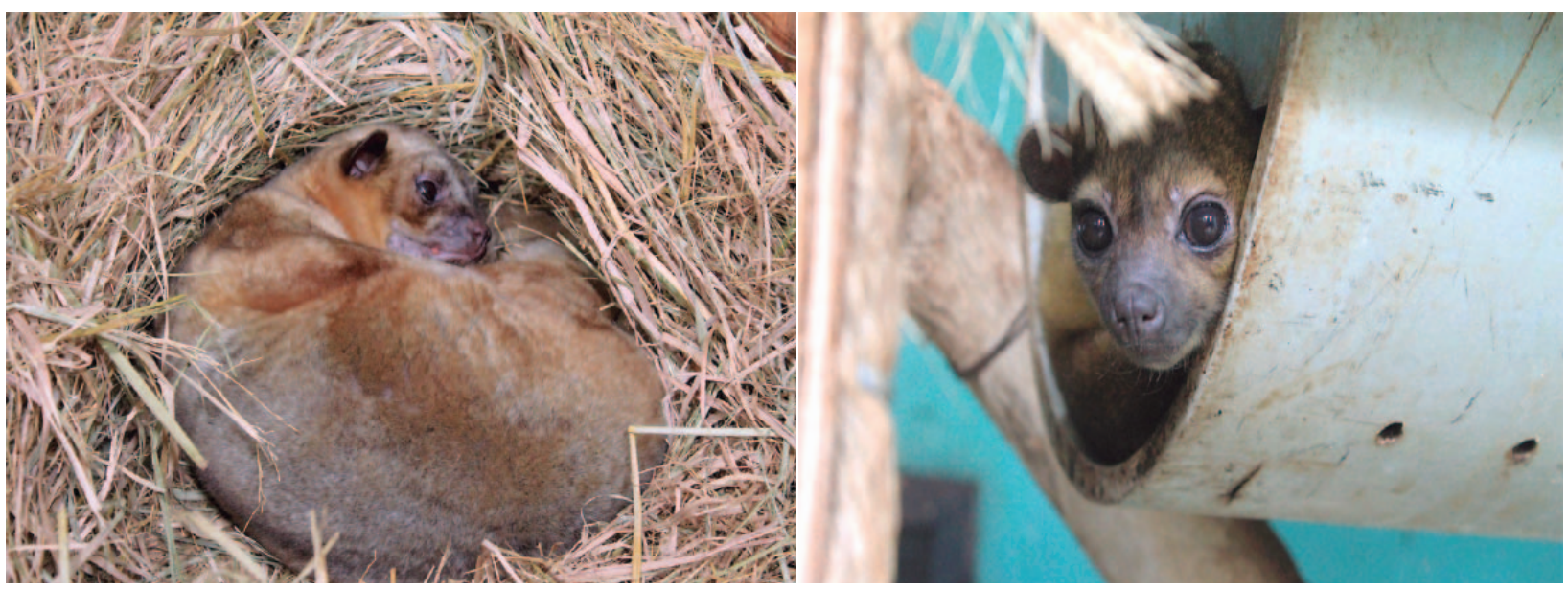

Figura 1. Ejemplares en cautiverio de Potos flavus adultos

la selva de Bolivia y la región de Mato Grosso en Brasil (9). Pesa, en promedio, 2500 gramos y tiene un requerimiento energético de $1800 \mathrm{~kJ}$ por día; por ello, para cubrir sus requerimientos de nitrógeno deben consumir grandes cantidades de frutas en relación a su peso, su tracto digestivo es similar al de un carnívoro sin grandes adaptaciones para una dieta vegetal, son exclusivamente nocturnos y recorren largas distancias en búsqueda de alimentos en las coronas de grandes árboles frutales ${ }^{(9-11)}$.

La presente investigación describe las características epidemiológicas y circunstancias en las cuales se produjeron cuatro accidentes de mordedura de "chosna" en comunidades rurales del departamento de Madre de Dios y, en los cuales, posteriormente, se identificó el virus de la rabia.

\section{EL ESTUDIO}

Se realizó un estudio descriptivo de cuatro casos de rabia en "chosna" ocurridos desde abril de 2012, los casos fueron captados como parte de la vigilancia epidemiológica del Ministerio de Salud del Perú. Adicionalmente, se utilizó una ficha elaborada por los autores con la finalidad de obtener mayor información. El Laboratorio de Referencia Regional (LRR) de Madre de Dios realizó el diagnóstico mediante la prueba de inmunofluorescencia directa (IFD) en muestras de tejido encefálico, dichos resultados fueron confirmados por el Laboratorio de Zoonosis Virales del Instituto Nacional de Salud del Perú, donde además se realizó la tipificación antigénica.

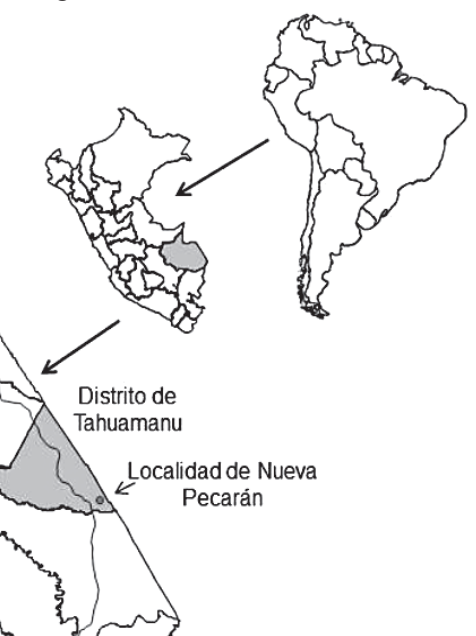

Figura 2. Ubicación de casos de rabia en Potos flavus reportados en el departamento de Madre de Dios, Perú 
Los casos ocurrieron en dos áreas; en la localidad de Nuevo Pacarán en la provincia de Tahuamanu y entre los kilómetros 84 y 104 de la carretera hacia Masuco, en la provincia de Tambopata (Figura 2). La primera se encuentra ubicada en el llano amazónico, posee un clima húmedo-cálido (temperatura media anual de 24 $25^{\circ} \mathrm{C}$ ). Es un centro poblado rural, según el censo del 2007, conformado por 30 viviendas y 110 habitantes distribuidos en forma dispersa, y está comunicada por una vía afirmada de $5,8 \mathrm{~km}$ con la carretera interoceánica. La actividad forestal extrae especies madereras valiosas, ocasionando el empobrecimiento cualitativo de estos bosques.

El tramo comprendido entre los kilómetros 84 y 104 de la carretera interoceánica hacia la ciudad de Masuco se encuentra ubicado en el distrito de Inambari. Esta zona es altamente transitada por la intensa actividad comercial, en los alrededores de la carretera se realiza actividad minera informal y artesanal.

\section{HALLAZGOS}

\section{CASO 1}

La agresión del "chosna" ocurrió en el dormitorio de una vivienda en la localidad de Nuevo Pacarán el 14 de abril de 2012 a las 02:00 h. La agredida, una mujer de 26 años, fue mordida en la mano derecha, presentó una herida profunda la cual no fue suturada; recibió tratamiento antirrábico con la vacuna nacional elaborada en cerebro de ratón lactante ( $C R L)$, se empleó el esquema reducido. El animal fue eliminado por el esposo (agricultor de 37 años), quien no aceptó la vacunación. La vivienda presentaba piso de tierra, pared de madera y techo de shapaja (material similar a hojas de palmeras) y se encontraba ubicada a 10 metros de vegetación abundante (bosques tropicales). La familia no criaba perros ni otros animales domésticos. Personal de la Dirección Regional de Salud realizó el estudio de contactos y accidentes de mordedura por animales silvestres en la localidad de Nuevo Pacarán y en localidades vecinas de La Novia, Shirigayoc, Santa María y Mavila, sin encontrar casos similares.

\section{CASO 2}

La agresión ocurrió en el patio de una vivienda en la localidad de Nuevo Pacarán, en la semana epidemiológica 19 del año 2013. La vivienda tenía piso y paredes de madera y techo de shapaja, se encontraba ubicada a 25 metros de vegetación abundante. La "chosna" agredió al perro (hembra de dos años) de la familia, la dueña interviene y elimina al animal agresor. No se reportaron personas mordidas, ni otros contactos.
El perro agredido y sus ocho crías también fueron eliminados a pesar de que estas últimas no tuvieron contacto con la "chosna".

\section{CASO 3}

La agresión ocurrió al margen de la carretera interoceánica, en la semana epidemiológica 21 del año 2013, al medio día, las personas afectadas reportan comportamiento agresivo de la "chosna". Los agredidos fueron una mujer de 27 años, mordida en rodilla derecha, por lo que presentó una herida profunda que no fue suturada. También estuvieron en contacto directo dos varones de 30 y 33 años, quienes participaron en la eliminación del animal agresor, uno de ellos con abrasiones en mano derecha. Las tres personas recibieron vacunación antirrábica (vacuna $C R L$ ) según el esquema reducido.

\section{CASO 4}

La agresión ocurrió en la carretera a Masuco a la altura del km 84, en la semana epidemiológica 24 del año 2013 en el patio de una vivienda con piso de tierra, pared de madera y techo de metal corrugado ("calamina"). La vivienda se encontraba ubicada a 1000 metros de vegetación abundante. El animal agresor se enfrentó con el perro (macho de un año), perteneciente a la familia, el cual fue mordido en la oreja derecha. La dueña de la vivienda y otros dos familiares eliminaron al "chosna". Durante la agresión no se reportaron mordeduras a personas, sin embargo, la dueña refirió salpicadura de sangre por lo que solicitaron vacunación para las tres personas que participaron en la eliminación. El perro de la familia fue eliminado.

No se pudo obtener información acerca del sexo de los animales agresores. Tampoco se reportó antecedente de contacto o visualización de "chosnas" alrededor de las casas o localidad. Todas las necropsias fueron realizadas en el Laboratorio de Referencia Regional de Madre de Dios (Tabla 1).

\section{DIAGNÓSTICO DE LABORATORIO}

Los análisis realizados en el Laboratorio Referencia Regional de Madre de Dios determinaron presencia de antígeno del virus de la rabia en las muestras de tejido encefálico, dichos resultados fueron corroborados en el Laboratorio de Zoonosis Virales del Instituto Nacional de Salud, mediante inmunofluorescencia directa. Adicionalmente, con la finalidad de determinar el reservorio al que correspondía el virus detectado se realizó la tipificación antigénica utilizando un panel de ocho anticuerpos monoclonales (Tabla 1). 
Tabla 1. Características de los casos por mordedura de Potos flavus "chosna" en Madre de Dios, Perú

\begin{tabular}{|c|c|c|c|c|c|c|c|}
\hline Caso & $\begin{array}{l}\text { Fecha y } \\
\text { hora }\end{array}$ & Localidad & $\begin{array}{l}\text { Circunstancias del } \\
\text { accidente }\end{array}$ & $\begin{array}{l}\text { Personas } \\
\text { contactadas }\end{array}$ & $\begin{array}{l}\text { Animales } \\
\text { contactados }\end{array}$ & $\begin{array}{l}\text { Sintomatología } \\
\text { del animal }\end{array}$ & $\begin{array}{l}\text { Variante } \\
\text { antigénica }\end{array}$ \\
\hline 1 & $\begin{array}{l}14 \text { de abril } \\
2012 \\
02: 00 \mathrm{~h}\end{array}$ & $\begin{array}{l}\text { Nuevo Pacarán } \\
\text { (distrito de } \\
\text { Tahuamanu) }\end{array}$ & $\begin{array}{l}\text { Animal ingresó a } \\
\text { dormitorio de vivienda } \\
\text { (ataque a persona) }\end{array}$ & 2 & 0 & Agresividad & NR \\
\hline 2 & $\begin{array}{l}5 \text { de abril } \\
2013 \\
04: 00 \mathrm{~h}\end{array}$ & $\begin{array}{l}\text { Nuevo Pacarán } \\
\text { (distrito de } \\
\text { Tahuamanu) }\end{array}$ & $\begin{array}{l}\text { Animal ingresó a patio } \\
\text { de vivienda (pelea con } \\
\text { perro doméstico) }\end{array}$ & 1 & 1 & Agresividad & ND \\
\hline 3 & $\begin{array}{c}23 \text { de mayo } \\
2013 \\
12: 00 \mathrm{~h}\end{array}$ & $\begin{array}{c}\text { Carretera a Mazuko } \\
\text { (km 104) (distrito de } \\
\text { Inambari) }\end{array}$ & $\begin{array}{c}\text { Encuentro y ataque en } \\
\text { carretera }\end{array}$ & 3 & 0 & Agresividad & NR \\
\hline 4 & $\begin{array}{l}13 \text { de junio } \\
2013 \\
20: 00 \mathrm{~h}\end{array}$ & $\begin{array}{l}\text { Carretera a Mazuko } \\
\text { (km 84) (distrito de } \\
\text { Inambari) }\end{array}$ & $\begin{array}{c}\text { Animal ingresó a patio } \\
\text { de vivienda (pelea con } \\
\text { perro doméstico) }\end{array}$ & 3 & 1 & Agresividad & NR \\
\hline
\end{tabular}

NR: nueva variante antigénica, no reportada por estudios previos, ND: no hubo muestra para realizar la caracterización antigénica.

\section{DISCUSIÓN}

Se presenta la ocurrencia de cuatro casos de rabia en Potos flavus "chosna" en el departamento de Madre de Dios en Perú, hallazgo que es una evidencia adicional de la emergencia de un nuevo reservorio del virus de la rabia en esta especie y que ha sido reportada previamente en el mismo departamento en el año $2007^{(12-14)}$.

Esta especie tiene características particulares en su organización social. Si bien pasan solos la mayor parte del tiempo, estos mamíferos se agrupan regularmente en sus guaridas. Tanto en cautiverio como en su hábitat natural, la "chosna" entra a su guarida antes de la salida del sol. Pernoctan en grupos sociales, usualmente en un número limitado de guaridas en el centro de su territorio, dichas guaridas se encuentran en agujeros naturales de grandes árboles ${ }^{(11)}$. Esta característica permite que la "chosna" se encuentre en contacto con murciélagos hematófagos y no hematófagos.

Comportamientos agresivos han sido observados entre miembros del mismo grupo social, normalmente ocurren entre machos adultos e involucran breves peleas y vocalizaciones agresivas que duran tres minutos o menos, y sin grave daño físico. La organización social de la "chosna" puede ser flexible y depende de su tamaño corporal y la presencia de predadores, lo cual pueden hacerlos más sociables con el objetivo de minimizar el riesgo de predación (11). Sin embargo, en los casos reportados, el comportamiento del "chosna" no fue normal desde el punto de vista biológico y social, por el contrario, se trataría de especímenes que presentaron agresividad, hiperactividad y cambios del comportamiento normal, dichas manifestaciones son frecuentes en cuadros clínicos de rabia en perros, gatos y ganado ${ }^{(15)}$.
Ninguno de los afectados reportó antecedentes de contacto alrededor de su hogar o en su comunidad con especímenes de "chosna", lo cual es compatible con los hábitos nocturnos exclusivos del animal. En todos los casos, el primer contacto fue con la ocurrencia del ataque. Es importante destacar el lugar y la hora de los encuentros, tres de ellos con ingreso del animal a viviendas humanas y otro en la cercanía de una carretera principal, además, uno de las agresiones ocurrió al mediodía. No se pudo determinar si otras personas del área tuvieron contacto visual previo con especímenes de "chosna".

Los hábitos alimenticios del animal alejan la posibilidad de invasión a áreas ocupadas por humanos, en búsqueda de alimentos. Si bien las actividades humanas vienen causando cambios severos en la ecología de Madre de Dios y existe invasión humana de áreas naturales que son nichos ecológicos de las "chosnas", consideramos que el principal motivo de los ataques es el desarrollo de un cuadro clínico de rabia, caracterizado por agresividad, desorientación, cambios del comportamiento e hiperactividad. Según el reporte de los agredidos, no se pudo determinar la presencia de otros síntomas sugestivos de rabia como parálisis faríngea, parálisis corporal, anorexia o depresión, los cuales serían difíciles de documentar por la rareza del contacto del humano con este mamífero ${ }^{(15)}$.

En muchas áreas de la Amazonía no existe ganado, que es la principal fuente de alimento para los murciélagos hematófagos, por ello, los mamíferos silvestres constituyen una fuente de alimentación (6). En la llanura amazónica como Madre de Dios las cuevas o cavernas naturales son raras, por lo que las colonias de Desmodus rotundus y otros murciélagos no hematófagos como la Tadarida brasiliensis colonizan 
huecos en los árboles ${ }^{(6,16)}$. En estas circunstancias los mamíferos que habitan en este ecosistema son potencial fuente de alimento para los murciélagos.

Por otro lado, existe evidencia acerca del papel como vector de rabia silvestre de los murciélagos no hematófagos (17-19). De los murciélagos no hematófagos analizados como parte de la vigilancia en algunos países, la proporción de murciélagos con anticuerpos contra el virus de la rabia varía de 3,1 a $5,4 \%$ en Argentina (17); $6,7 \%$ en los Estados Unidos ${ }^{(20)}$ y $1 \%$ en Brasil (21). En la presente serie no pudimos determinar la forma de exposición al virus o comprobar historia o evidencia de mordeduras en las "chosnas".

En el Perú, se han descrito cuatro linajes filogenéticos del virus de la rabia circulante en poblaciones de murciélago hematófagos, además de la identificación de tres potenciales nuevos linajes en reservorios diferentes a murciélagos y no relacionados con alguna variante conocida del virus, siendo una de dichas variantes aislada de un espécimen de "chosna" en el departamento de Madre de Dios ${ }^{(13)}$. Estos resultados son congruentes por lo reportado en nuestro estudio, donde en tres de los cuatro casos estudiados, el análisis filogenético no identificó ninguna de las variantes conocidas en murciélagos o en perros.

Estudios han reportado la presencia del virus de la rabia en otras especies de mamíferos silvestres como en el Callithrix jacchus (titi) ${ }^{22}$. En Brasil se ha identificado en esta especie el virus de la rabia de una variante antigénica no conocida, incluso se han reportado infección en humanos con esta variante asociada al $C$. jacchus ${ }^{(23)}$. En México, dos ejemplares de Nasua narica (coati de hocico blanco) presentaron rabia y se identificó a la variante antigénica 9 , la cual ha sido asociada con rabia enzoótica en murciélago Tadarida brasiliensis en México y Estados Unidos (24).

Con la información disponible no es posible determinar la forma de infección, sin embargo, su cercanía taxonómica con los mapaches (Procyon lotor) y los antecedentes de rabia en otros mamíferos silvestres de América Central y Sudamérica, sugiere que el Potos flavus podría ser un reservorio emergente de la rabia en su ciclo silvestre en el Perú. Se recomienda estudios que ayuden a explicar el rol de la "chosna" como reservorio del virus rábico en la cadena epidemiológica de la rabia silvestre, y que determinen si los casos presentados se encuentran relacionados, permitiendo una mejor descripción de la forma de presentación de la rabia en esta especie.

En conclusión, el hábitat de la "chosna" tiene una región nuclear, periférica y de dispersión las cuales, en condiciones naturales, se encuentran en equilibrio ecológico ${ }^{(6,11)}$. En dicho foco cohabita con especies de murciélagos hematófagos y no hematófagos quienes son los principales vectores de la rabia en el ciclo silvestre (6). La "chosna" tiene un comportamiento social que lo hace poco accesible al humano, sin embargo, con el desarrollo del cuadro clínico de rabia incrementa la posibilidad de contacto y ataques a humanos y animales domésticos. Este reporte evidencia la ocurrencia de cuatro casos de rabia en "chosna" siendo la infección en estos mamíferos rara. El linaje del virus rábico identificado no se encuentra relacionado a variantes descritas en murciélagos hematófagos y no hematófagos.

Agradecimientos: a la División de Zoología del Parque de las Leyendas de Lima por permitirnos acceder a sus instalaciones para la toma de fotografías de los especímenes de Potus flavus y a la Lic. Narda Eguileta Arenas directora de Epidemiología DIRESA Madre de Dios en Perú.

\begin{abstract}
Contribuciones de autoría: EVL y FRR participaron en la concepción y diseño del artículo, recolección/obtención de resultados, análisis e interpretación de datos, redacción del artículo, revisión crítica del artículo y aprobación de su versión final. RLI, JAL y MYM participaron en la revisión crítica del artículo y aprobación de su versión final.
\end{abstract}

Conflictos de interés: los autores declaran no tener conflictos de interés

Fuentes de financiamiento: autofinanciado

\section{REFERENCIAS BIBLIOGRÁFICAS}

1. Udow SJ, Marrie RA, Jackson AC. Clinical features of dog- and batacquired rabies in humans. Clin Infect Dis. 2013;57(5):689-96. doi: 10.1093/ $\mathrm{cid} / \mathrm{cit} 372$.

2. Nel L. Discrepancies in data reporting for rabies, Africa. Emerg Infect Dis. 2013;19(4):529-33. doi: 10.3201/ eid1904.120185.

3. Streicker DG, Recuenco S, Valderrama W, Gomez Benavides J, Vargas I, Pacheco V, et al. Ecological and anthropogenic drivers of rabies exposure in vampire bats: implications for transmission and control. Proc Biol Sci. 2012;279(1742):3384-92.
4. Vigilato MA, Cosivi O, Knöbl T, Clavijo A, Silva HM. Rabies update for Latin America and the Caribbean. Emerg Infect Dis. 2013;19(4):678-9. doi: 10.3201/eid1904.121482.

5. Warner CK, Zaki SR, Shieh WJ, Whitfield SG, Smith JS, Orciari LA, et al. Laboratory investigation of human 
deaths from vampire bat rabies in Peru. Am J Trop Med Hyg. 1999;60(3):5027.

6. Gilbert AT, Petersen BW, Recuenco S, Niezgoda M, Gómez J, LagunaTorres VA, et al. Evidence of rabies virus exposure among humans in the Peruvian Amazon. Am J Trop Med Hyg. 2012;87(2):206-15. doi: 10.4269/ajtmh.2012.11-0689.

7. Schneider MC, Romijn PC, Uieda W, Tamayo H, da Silva DF, Belotto A, et al. Rabies transmitted by vampire bats to humans: an emerging zoonotic disease in Latin America? Rev Panam Salud Publica. 2009 Mar;25(3):260-9.

8. Salmón-Mulanovich G, Vásquez A, Albújar C, Guevara C, Laguna-Torres VA, Salazar M, et al. Human rabies and rabies in vampire and nonvampire bat species, Southeastern Peru, 2007. Emerg Infect Dis. 2009;15(8):1308-10. doi: 10.3201/eid1508.081522.

9. Julien-Laferrière D. Foraging strategies and food partitioning in the neotropical frugivorous mammals Caluromys philander and Potos favus. J Zool Lond. 1999;274:71-80.

10. Kays RW. Food preferences of kinkajous (Potos flavus): a frugivorous carnivore. J Mamal. 1999;80(2):58999.

11. Kays RW, Gittleman JL. The social organization of the kinkajou Potos flavus (Procyonidae). J Zool Lond. 2001;253:491-504.

12. Murciélago vampiro responsable del brote de rabia humana ocurridos en el distrito de Inambari-Madre de Dios. Boletín del Instituto Nacional de Salud. 2007;4(7):2-3.
13. Condori-Condori RE, Streicker DG, Cabezas-Sanchez C, Velasco-Villa A. Enzootic and epizootic rabies associated with vampires bats, Peru. Emerg Infect Dis. 2013;19(9). doi: 10.3201/eid1809.130083.

14. Navarro A, Bustamante J, Sato A. Situación actual y control de la rabia en el Perú. Rev Peru Med Exp Salud Publica. 2007;24(1):46-50.

15. Thiptara A, Atwill ER, Kongkaew W, Chomel BB. Epidemiologic trends of rabies in domestic animals in Southern Thailand, 1994-2008. Am J Trop Med Hyg. 2011;85(1):138-45. doi: 10.4269/ajtmh.2011.10-0535.

16. Turmelle AS, Allen LC, Jackson FR, Kunz TH, Rupprecht CE, McCracken GF. Ecology of rabies virus exposure in colonies of brazilian free-tailed bats (Tadarida brasiliensis) at natural and man-made roosts in Texas. Vector Borne Zoonotic Dis. 2010;10(2):16575. doi: $10.1089 / \mathrm{vbz} .2008 .0163$.

17. Piñero C, Gury Dohmen F, Beltran F, Martinez L, Novaro L, Russo S, et al. High diversity of rabies viruses associated with insectivorous bats in Argentina: presence of several independent enzootics. PLoS Negl Trop Dis. 2012;6(5):e1635. doi: 10.1371/journal.pntd.0001635.

18. Favic M, de Mattos CC, Yung V, Chala E, López LR, de Mattos CA. First case of human rabies in Chile caused by an insectivorous bat virus variant. Emerg Infect Dis. 2002;8(1):79-81.

19. Favic M, Yung V, Pavletic C, Ramírez E, de Mattos C, de Mattos CA. Rol de los murciélagos insectívoros en la transmisión de la rabia en Chile. Arch Med Vet. 1999;31(2):157-65.
20. Patyk K, Turmelle A, Blanton JD, Rupprecht CE. Trends in national surveillance data for bat rabies in the United States: 2001-2009. Vector Borne and Zoonotic Dis. 2012;12(8):666-75.

21. Albas A, Souza EA, Picolo MR, Favoretto SR, da Gama AR, Sodré MM. Os morcegos e a raiva na região oeste do Estado de São Paulo. Rev Soc Bras Med Trop. 2011;44(2):201-5.

22. Aguiar TD, Costa EC, Rolim BN, Romijn PC, Morais NB, Teixeira MF. Risco de transmissão do vírus da raiva oriundo desagui(Callithrixjacchus), domiciliado e semidomiciliado, para o homem na região metropolitana de Fortaleza, Estado do Ceará. Rev Soc Bras Med Trop. 2011;44(3):356-63.

23. Favoretto SR, de Mattos CC, de Mattos CA, Campos AC, Sacramento DR, Durigon EL. The emergence of wildlife species as a source of human rabies infection in Brazil. Epidemiol. Infect. 2013;141(7):1552-61.

24. Aréchiga-Ceballos N, Velasco-Villa A, Shi M, Flores-Chávez S, Barrón B, Cuevas-Domínguez E, et al. New rabies virus variant found during an epizootic in white-nosed coatis from the Yucatan Peninsula. Epidemiol Infect. 2010;138(11):1586-9. doi: 10.1017/ S0950268810000762.

Correspondencia: Franco Romani Romani Dirección: Calle Cápac Yupanqui 1400, Jesús María. Lima, Perú

Teléfono: 990630678

Correo electrónico:fromanir@gmail.com

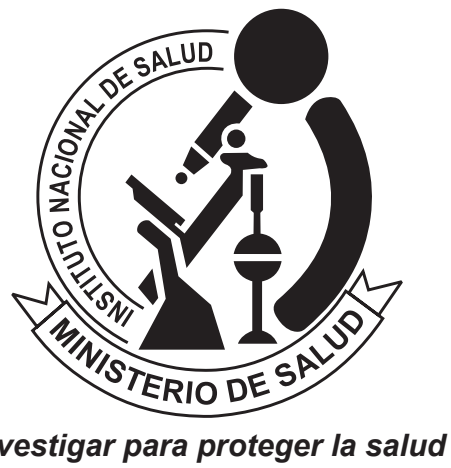

REVISTA PERUANA DE MEDICINA EXPERIMENTAL Y SALUD PÚBLICA CUMPLIENDO SUS METAS Y PROYECTÁNDOSE AL FUTURO

\section{Visite los contenidos de la revista en: www.ins.gob.pe/rpmesp}

